\title{
Meisner ve Adler'in Oyuncunun Sahne Üzerindeki Gerçeklik Algısına Yaklaşımlarının Değerlendirmesi
}

\section{Comperative Evaluation of Approaches of Meisner and Adler in the Context of Actor's Perception of Reality on Stage}

Burçak DİLEKLI I ${ }^{1}$ (])

DOI: $10.26650 / C O N S 2020-0003$

'Sanatta Yeterlilik Öğrencisi, İstanbul Üniversitesi Devlet Konservatuvarı, Sahne Sanatları Bölümü, Tiyatro Anasanat Dalı, İstanbul, Türkiye

ORCID: B.D. 0000-0002-3995-6427

Sorumlu yazar/Corresponding author: Burçak Dilekli,

İstanbul Üniversitesi Devlet Konservatuvarı, Sahne Sanatları Bölümü, Tiyatro Anasanat Dalı, İstanbul, Türkiye

E-posta/E-mail: burcakdilekli@gmail.com

Başvuru/Submitted: 18.03 .2020

Revizyon Talebi/Revision Requested: 11.05.2020

Son Revizyon/Last Revision Received: 18.05.2020

Kabul/Accepted: 21.05 .2020

Online Yayın/Published Online: 04.06.2020

Atıf/Citation: Dilekli, B. (2020). Meisner ve Adler'in oyuncunun sahne üzerindeki gerçeklik algısına yaklaşımlarının değerlendirmesi. Konservatoryum - Conservatorium, 7(1), 25-40 https://doi.org/10.26650/CONS2020-0003

\section{öz}

Bu makalede, Sanford Meisner ve Stella Adler'in oyunculuk yaklaşımlarının oyuncunun sahne üzerindeki gerçeklik algısı bağlamında karşılaştırarak değerlendirilmesi amaçlanmaktadır. Grup Tiyatrosunun kurucuları arasında yer alan ve Stanislavski'nin birinci dönem çalışmaları üzerine kurulu bir oyunculuk anlayışı belirlemiş olan bu ikili, Adler'in Paris'te Stanislavski ile yaptığı çalışmalardan öğrendiklerini grup üyeleriyle paylaşması sonucu coşku belleğini bırakıp verili koşullara yönelmişlerdir. Grup Tiyatrosu içindeki tartışmalarda Strasberg'e karşı olarak Adler'in yanında yer alan Meisner, sonraki dönemde geliştirdiği oyunculuk metodunda Adler gibi coşku belleğine yer vermemiştir. Ancak ilerleyen süreçte, başlangıçta Stanislavski'nin oyunculuk anlayışından yolan çıkan bu iki isim, oyuncunun sahne üzerindeki gerçekliği bağlamında birbirinden ayrılmıştır. Kendi metotları üzerine yazdıkları birincil kaynaklardan yola çıkılarak bu makalede Adler ve Meisner'in oyunculuk yaklaşımlarının hangi açılardan birbirinden ayrıldığı kendi metotlarında kullandıkları temel kavramlar ele alınarak incelenmiş ve birbiriyle karşılaştırma yoluna gidilmiştir. Bunun sonucunda, Meisner ve Adler'in oyuncunun sahne üzerindeki gerçeklik algısına yaklaşımlarının birbirinden oldukça farklı olduğuna ulaşıımış ve bu farklıklar açıklanmıştır.

Anahtar Kelimeler: Meisner, Adler, Gerçeklik

\section{ABSTRACT}

This article aims to evaluate the Sanford Meisner and Stella Adler's acting methods comparatively by underlying their approach on the understanding of actors' reality on stage. This duo, who was among the founders of the Group Theater and determined a sense of acting based on Stanislavski's first term work, left working with affective memory and turned to the given circumstances after Adler shared what she learned from Stanislavski in Paris. The discussions inside the group ended up with the departure of Strasberg from the group, and Meisner also joined Adler and was against affective memory. However, these two names, who initially started off from Stanislavski's acting approach, were separated from the context of the actor's reality on the stage. Based on the primary sources they wrote on their own methods, in this article, the aspects of the acting approaches of Adler and Meisner are analyzed by examining the 
basic concepts they use in their own methods and comparing them with each other. As a result of this, Meisner and Adler's approach to the actors' perception of reality on the stage is quite different from each other and will try to be explained within the frame of this paper.

Keywords: Meisner, Adler, Reality

\section{EXTENDED ABSTRACT}

The approaches of Stella Adler and Sanford Meisner, who created their own acting methods in the process after the break of Strasberg from the Group Theater, are quite different from each other, although they are accepted as based on Stanislavski. This difference distinguishes both their view of the actor's reality on stage and also some factors such as character, imagination, action, and relationship with partner that provides reality for the actors. Stella Adler added Stanislavski's approach to her own approach by interpreting the sense of memory, action, imagination and justification of the action, which she thought determined the reality of the actor on the stage. The character, imagination, action and justification that Stella Adler handles one by one is based on the actors' studies that make them as realistic as possible by elaborating, analyzing and working on them. In her book "The Art of Acting", Adler (2006) deals with the diversification and analysis of actions one by one, by analyzing them separately, and asks the actor to master, as much as possible, the physical actions he or she will perform on the stage. According to Meisner (1987), the actions that arise from the impulsive response on the stage that the actor will give to him or her by observing his partner are designed in advance according to Adler. In this context, Meisner's understanding of the reality that the actor has built on the "truthfully living" by investing in the reality of doing here-and-now is quite different from the actions that Adler wants the actor to design and perform.

Similarly, an important dimension of reaching reality on stage is reality in character. Although Adler says that the character is made up of what the actor did on the stage, this is quite different from the character that Meisner said appeared in the actions. This is because Adler chooses the way to analyze and construct the character in the sequel, just like in actions and imagination. According to Stella Adler's approach, the actors must be aware and imagine all the details of a character's past, social status, childhood, family, education, occupation, professional experience and personal relationships to create the character (Adler, 2006).

Another important difference between Meisner and Adler is the difference in imagination and given circumstances. According to Adler, the reality of the actor on the stage is 
directly connected to the imagination, and not passed through the imagination and considered as the real "lie"; according to Meisner, the actor on the stage should not break from the present time, and should not allow the formation of a "head" work by returning to his or her mind (Meisner ve Longwell, 1987). Only by getting rid of the manipulation of his or her mind, the actor can actually live here-and-now, in Meisner's words, "living truthfully". Unlike Miesner, who underlines that acting lies in the impulses and that the actor must get rid of mentality; for Adler, not a single word from the mouth of the actor should not come out of the imagination (Adler, 2006). The more detailed the actor details something in his or her imagination, the greater reality he or she reaches.

Finally, Meisner and Adler, who base their approaches on what actors do on the stage for different reasons, differ on what the actor's reality of doing is based on. According to Adler (2006), the actions performed by the actor are based on personal reasons that the actor decides personally; for Meisner, what happens to the actor and his or her response depends entirely on the other person. The actor cannot go to any justification other than given circumstances. Therefore, contrary to Adler, who states that there will be a reality proportional to the good justification of the actions, Meisner suggests that the actor will only respond truthfully by observing his or her partner well and responding accordingly. 


\title{
Giriş
}

\begin{abstract}
“Stanislavski’yi oyunculuk konusunda önemli keşiflere —yani bir rolün temsil edilmesinin değil, sahne üzerindeki bir rolde yaşamın yaratılmasının önemine ve set, kostüm ve efektle otantiklik yoluyla aktörlerin dışsal gerçekliği hissetmelerini sağlamanın bir yolu olarak, duygu durumun yaratılmasının oyunculukta yüksel gerçeğin ortaya çıkacağına- yönlendiren Anton Çehov'un oyunları üzerindeki çalışmalar oldu" (Whyman, 2012, s. 51).
\end{abstract}

Stanislavski tarafindan 1900'lerin başında Rusya' da geliştirilen 'sistem', temsili oyunculuğa karş1 realizm doğrultusunda geliştirilen oyunculuk üzerine yapılmış araştırma ve çalışmalardan oluşan bir yöntemdir. Oyuncunun, duyguları dışarıdan taklit etmesi, '-mış gibi' yapmasının önüne geçilmek istenmiş ve 'coşku belleği' (affective memory) karakterin duygularını gerçekten duyumsaması amacıyla kullanılan çalışmalardan biri olarak benimsenmiştir. Fakat Stanislavki'nin, çalışmalarını eylem ve verili koşulların ${ }^{1}$ üzerine kaydırmasıyla; gerçek coşkulara fiziksel eylemlerle ulaşılabildiği düşüncesi son döneminde baskın hale gelmiştir. Tüm bu yöntemler oyuncunun sahne üzerinde 'gerçekliğe' ulaşması amacıyla kullanılmıştır.

Bu bağlamda, Sanford Meisner ve Stella Adler'in, takipçisi olarak kabul edildikleri Stanislavski gibi oyuncunun sahne üzerindeki 'gerçeklik algısı'na² yönelik çalı̧̧malarının kendi yaklaşımlarının temelini oluşturduğu görülmektedir. Ancak, 'organiklik', 'doğallık', 'sahicilik' gibi ifadelerle desteklenen bu gerçeklik algısının iki yaklaşımca oldukça farklı şekillerde ele alınıyor oluşu oyunculuk yöntemlerini hem sahne üzerinde hem de sahne gerisindeki pratikler göz önüne alındığında birbirinden oldukça ayrıştırır. Bu nedenle, bu makale Meisner ve Adler'in oyuncunun sahne üzerindeki gerçeklik algısına dair yaklaşım ve yöntemlerini karakter, hayal gücü, eylem, gerekçelendirme ve benzeri anahtar kavramlar üzerinden inceleyerek karşılaştırmayı amaçlamaktadır.

\section{Sanford Meisner, Stella Adler ve Grup Tiyatrosu}

Sanford Meisner Erasmus Lisesi’ndeki eğitiminin ardından piyano öğrenimi göreceği Damrosch Müzik Enstitüsü’ne girdiğinde henüz aklında oyunculuk eğitimi yoktur. An-

1 Jean Benedetti, Stanislavski'nin kitabının İngilizce basımlarında çeşitli hatalar bulunduğunu fark ederek kitabı "Bir Oyuncunun Çalışması" ismiyle Rusça'dan İngilizce'ye yeniden çevirmiştir ve bu çalışmada "verili koşullar', genel itibariyle oyundaki gerçekler, olaylar, dönem, eylemin yeri ve zamanı gibi oyuncuya verilen tüm koşullar olarak tanımlanmaktadır (Stanislavski, 2008, s. 52-53).

2 Bu makalede, İngilizce kaynaklarda Meisner'in kullandığı haliyle reality, truthfullness olarak ifade edilen kavram, Türkçe'ye 'samimiyet' ya da 'dürüstlük' olarak çevrilmek yerine 'gerçeklik algısı' kavramıyla ifade edilmiştir. Ayrıca metin boyunca yapılan İngilizce çeviriler makale yazarı tarafından yapılmıştır. 
cak 19 yaşına geldiğinde oluşan profesyonel anlamda oyunculuk yapma düşüncesi onu Guild Tiyatrosu'na başvurmaya yöneltir. Tiyatroya kabul edilen Meisner bir yandan Guild Tiyatrosu Oyunculuk Okulu'nda eğitim alırken bir yanda da tiyatronun oyunlarında yer almaya başlar. Bu süreçte besteci arkadaşı Aaron Copland tarafindan Harold Clurman'la tanıştırılır ve bu tanışma Lee Strasberg'i tanımasına vesile olur. Harold Clurman ve Lee Strasberg, turneye geldikleri Amerika'da iltica ederek ülkelerine dönmeyen Moskova Sanat Tiyatrosu oyuncuları Richard Boleslavski ve Maria Ouspenskaya'nın 1924 yılında kurdukları Amerikan Laboratuvar Tiyatrosu'nun (American Laboratory Theatre) yönetmenlik alanında eğitim alan öğrencileridir. Birkaç yıl süren kaynak yaratma süreci sonunda Meisner, Strasberg, Clurman ve bir diğer Guild Tiyatrosu çalışanı Cherly Cawford ile birlikte 1931 yılında seçtikleri yirmi beş oyuncunun katılımıyla Grup Tiyatrosu'nu (Group Theatre) kurar (Meisner ve Longwell, 1987).

Bu kurucu grubun içinde Stella Adler de vardır. Adler kendisi gibi oyuncu olan babası Jacop Adler'in etkisiyle oyunculukla çok genç yaşta tanışmış, Amerikan Laboratuvar Tiyatrosu'nda oyunculuk eğitimi almıştır (Adler, 2006). Adler, Amerikan Laboratuvar Tiyatrosu'nda eğitim alan diğer grup üyeleri Ruth Nelson, Eunice Stoddard, Lee Strasberg ve Harold Clurman ile birlikte Grup Tiyatrosu'nda Stanislavski kaynaklı bir oyunculuk anlayışı sürdürmeye başlar. Bu oyunculuk yaklaşımı Ouspenskaya ve Boleslavski'nin öğrettiği haliyle Stanislavski’nin çalışmalarının ilk dönemi üzerine kuruludur. Grup, çalışmalarının bir bölümünü New York şehri dışında Stanislavski’nin oyunculuk egzersizleri ve tiyatro oyunları üzerinde çalışarak geçirir, sonbaharda tekrar New York'a dönerek çalıştıkları oyunları sahneler. Grubun sanat yönetmenliğini Harold Clurman yürütürken, baş oyunculuğu Stella Adler, baş yönetmenliği Lee Strasberg yapmaktadır. Meisner de hem eğitmenlik yapmakta hem de oyunlarda yer almaktadır. Bu yapı içinde, Grup Tiyatrosu aktif olmaya başladıkları ilk andan itibaren Amerikan tiyatrosu ve oyunculuk anlayışııı derinden etkilemeyi başarmıştır. Ancak, kurulmasından üç yıl kadar sonra dağılma sürecine girer. Bu sürecin, grubun kurulmasından üç y1l sonra Paris'te Stanislavski ile beş haftadan fazla bir süre birebir çalışma imkânı bulan Stella Adler'in, sistemin kendisi ve grup üyelerince sıkıntı yaşamalarına neden olduğunu söylediği yönlerini sorgulamasıyla başladığı söylenebilir. Stanislavski ile Paris'te yaptığı çalışmalar sonucu Grup Tiyatrosu'na dönen Stella Adler, grup üyeleriyle Stanislavski'nin yönteminin vurgusunun coşku belleğinden 3 ‘verili

3 'Coşku Belleği', oyuncunun sahne üzerinde duygularını, geçmişte yaşadığı bir olayı hatırlayarak uyarmasına dayalı bir tekniktir (Özüaydın, 2015, s. 25). 
koşullara' kaydığını paylaşır. Stanislavski'ye göre gerçek hislere ulaşmanın yolu 'verili koşullardan' geçmektedir. Çalışmalarını coşku belleği üzerine kuran Strasberg bu görüşe karşı çıksa da grup içindeki pozisyonu etkilenir ve bir yıl sonra 1935 yılında Grup Tiyatrosu'ndan ayrılır. Bu gelişmeler sırasında, Meisner, Stella Adler'in yanında yer almış ve coşku belleği Meisner'in oluşturduğu metotta yer almamıştır (Meisner ve Longwell, 1987).

Burada ilginç olan, aynı noktadan yola çıkarak Stanislavki'nin oyunculuk tekniği üzerine çalışan grup üyelerinin zamanla birbirinden uzaklaşarak bambaşka bakış açılarına sahip olmalarıdır. Bu dönemde, Neighourhood Playhouse'da çalışmaya başlayan Meisner, 1936 yılında Drama Bölüm Başkanlı̆̆ı'na gelerek kendi oyunculuk metodunu bu ylllarda şekillendirir ("The Sanford Meisner Center", 2018). Stella Adler kendi stüdyosunu açar, Strasberg ise bir süre sonra daha sonra başına geçeceği Actors Studio'da çalışmaya başlar. Devam eden yıllarda, her biri kendi oyunculuk metodunu Stanislavski'nin oyunculuk tekniğini başka şekillerde yorumlayarak oluşturur. Strasberg'in oyuncunun coşku belleği yardımı ile sahne üzerinde gerçekliğe ulaşabileceği iddiasına karşı gelen Adler'i destekleyen Meisner'in oyuncunun sahne üzerindeki 'gerçek' algısına dair yaklaşımı ise zaman içinde Adler'den tamamen farklılaşır.

\section{Adler ve 'Gerçeklik' Üzerine}

"Sanattaki gerçeklik, koşullardaki gerçekliktir. [...] Oyuncu ne denli iyiyse koşulları da o denli özenle yaratır" (Adler, 2006, s. 30-32).

Stanislavski'yle çalışma ve 'yöntem' ile tanışma firsatı bulduğunu belirten Adler (2006) 'Oyunculuk Sanatı' (The Art of Acting) isimli kitabında oyunculuğun sırrının bir şeyi yapmakta, olabildiğince 'sahici bir biçimde yapmakta' olduğunu söyler (Adler, 2006, s. 47). Peki bu sahicilik nasıl sağlanacaktır? Adler'e göre gerçeklik eylemler aracılığıyla var olur; bu nedenle oyuncu oynayacağı metindeki eylemlere hâkim olmalı, 'Eyleminiz nedir?' sorusuna cevap verebilmelidir (Adler, 2006, s. 49). Adler'e göre her eylemin kendine özgü hazırlıkları ve kendine özgü sistemleri vardır. Bir şişeyi kaldırmak isteyen oyuncunun şişeyi nasıl kaldıracağını kendisine sorarak en az üzerinde yirmi dakika çalışmasını ve kaslarının bu hareketler zincirini ezberleyerek kas hafızasına yerleştirmesini söyler. $\mathrm{Bu}$, eylemlerin en ince ayrıntısına kadar analiz edildiğini ve tasarlandığını göstermektedir. Ayrıca, oyuncunun sahne üzerindeki eylemleri, seyirciyi inandırmaktan ziyade oyuncunun kendisinin inanacağı biçimde olmalıdır; böylelikle sahne üzerinde oyunculuğunun içten ve sahici olması sağlanır. Bu amaçla, oyuncu ayakkabısındaki hayali bir 
çamuru temizlemek, elinde tutkal varmışçasına ellerini yıkamak gibi aksiyonlar çalışarak kassal belleğin duyumsal gerçeğini öğrenmelidir (Adler, 2006, s. 55).

Buna göre, Adler'in oyuncunun bir eylemi gerçekten yapması için bu eylemi tüm detaylarıyla çalışması gerektiği fikrinden yola çıkması, eylemin kendiliğindenliğini ortadan kaldırmakta ve eylemi bir tasarının sahici biçimde gerçekleştirilmesine dönüştürmektedir. Adler'e göre, oyuncunun '-mış gibi yapma', bir ruh halini 'oynama' hali onun sahnede gerçekleştirdiği eylemleri fizikselleştirerek kendini korumakta başarısız olmasının muhtemel bir sonucudur. Bunu önlemek üzere oyuncunun eylemler üzerine çalışmasının üç aşaması vardır. Oyuncu ilk olarak kendisine o eylemi yapıp yapmadı̆̆ını sormalıdır. İkincil olarak, eylemin yapıldığını görüp görmediğini kendine soran oyuncu bu iki soruya da olumsuz yanıt verirse üçüncü seçenek olarak hayal gücüne başvurulmalıdır (Adler, 2006, s. 95). Böylelikle eylemi daha önce hiç gerçekleştirmemiş ya da tanık olmamış olmasına rağmen eylemi yapışında gerçekliğe ulaşmanın bir yolunu bulacağını düşünür.

Oyuncunun, eylemi gerekçelendirme yoluyla kendisini harekete geçirip eyleme yöneltmesi ve duyguyu yaşamasını sağlaması gerektiği söyleyen Adler, bu nedenle eylemi yaratırken ikincil amacın gerçekleştirilen eyleme 'neden yaratmak' olduğunu belirtir. Gerçekleşen eylemin nasıl gerçekleşeceği de bu gerekçelendirmeye bağlı olarak değişir. Buradaki gerekçelendirmeyi metnin verili koşullarından ayrı bir yere koyan Adler için gerekçe, metnin verdiği değil oyuncunun yarattığı nedenlerdir. Bu gerekçelendirmenin sadece hazırlık sürecini değil oyuncunun sahne üzerinde bulunduğu sürenin tamamını kapsayacak şekilde durmaksızın devam etmesi gerektiğinin ve yapılan her bir eylemin bu gerekçelere bağlı olmasının eylemin sahiciliğini belirlediğinin altını çizer. Eylemler metnin verdiği bilgiler yerine oyuncunun 'Neden?' sorusuna verdiği kişisel cevaplar ve buna bağlı fikirler üzerine kurulmuş olur (Adler, 2006, s. 117-125).

"Bir gerçek hayal gücünüzden geçene kadar yalandır" (2006, s. 54) diyen Adler için oyuncunun sahne üzerinde sahici olabilmesi için en önemli bir diğer şart hayal gücünün etkin kullanımıdır. Oyuncu kullandığı her nesneyi hayal gücünden geçirmeli, sahne üzerindeki tüm nesneler bu yolla anlam kazanmalıdır. Adler'e göre "sahnede gördüklerimizin ya da kullandıklarımızın yüzde doksan dokuzu hayal gücünden gelir; her sözcük, her hareket hayal gücünün süzgecinden geçirilmelidir” (s. 53). Seyircinin görebileceği bir gerçeklik yaratmak ancak oyuncunun da anlattığı şeyi önce kendi hayalinde canlı ve gerçek şekilde görebilmesine bağlıdır. Ona göre, gerçek duygular fiziksel eylemlerin 
sonucu olduğu gibi oyunun koşullarında ve hayal gücü sayesinde de bulunabilir. Bir oyuncunun sahnede sahici olarak var olabilmesi için hayal gücünün yardımı gereklidir. Oyuncunun bir limon ağacına ihtiyacı varsa ve onu hiç görmemişse kendine hayal gücü aracılığıyla bir tane yaratabilmelidir. Oyuncu hayalindeki limon ağacını ne kadar ayrıntılı hale getirirse onu görmüş olduğuna o denli çok inanacaktır. Bu amaçla, oyuncu hayal gücü üzerinde sürekli çalışmalı ve onu geliştirmelidir (Adler, 2006, s. 58).

Son olarak, Adler'e göre karaktere dair bir gerçeklik yaratmak isteyen oyuncu, karakterin geçmişi, sosyal statüsü, çocukluğu, ailesi, aldığı eğitim, mesleği ve mesleki tecrübesi ve kişisel ilişkilerinin tüm ayrıntılarını farkında olmalı ve hayal etmelidir. Bir karaktere çalışmanın ilk basamağı ise daima onun mesleği olmalıdır. Karakterin yaratımında Adler'in bir diğer ortaya koyduğu yöntem karakter unsurlarını belirlemektir. Üzerine çal1ş1lmaya değer unsurlar Adler (2006, s. 155-170) tarafından kaygısız, sempatik, sorumlu, maceraperest vb. gibi çeşitli sıfatlarla sıralanır. Dolayısıyla, karakter eylemlerle belirmek yerine analiz edilerek yapılan bir çalışma sonucu tercihlerle belirlenmiş olur.

\section{Meisner ve Gerçeklik}

“Oyunculuğun temeli yapma gerçekliğidir” (Meisner ve Longwell, 1987, s. 17).

Oyunculuğun 'verili koşullar altında gerçekten yaşama' becerisine bağlı olduğunu düşünen Meisner'e göre verili koşullar yazar tarafından oyunun dünyasına ait olarak verilen bilgiler bütünüdür. Meisner, verili koşullarla ilgili olarak 'Oyunculuk Üzerine' (On Acting) isimli kitabında zaman zaman 'hayali verili koşullar' zaman zaman ise 'verili koşullar' ifadelerini kullanmaktadır. Ancak 'hayali' kelimesi ile bahsedilen oyuncunun metinden bağımsız olarak kendi hayal gücüne dayanarak oluşturduğu koşullar değil metne dair, yazılı koşulların ifadesidir (Williams, 2018, s.10). Barter'ın da altını çizdiği gibi Meisner'e göre oyuncu sahnede oynama sırasında kulise doğru baktığında oyunun hayali dünyasına ait şeyleri değil sahne çalışanlarını görmelidir (Santana, 2006). Meisner'in öğrencilerinden biri olan Williams da öğrenciliği sırasında sınıfta bir öğrencinin sahneye çıktığını, Meisner'in sahne çalışması sırasında pencereden dışarı bakan oyuncuya dışarıda ne gördüğünü sorduğunu ve bunun üzerine oyuncunun Alpleri, tepeleri ve yağan karı gördüğ̈nü anlatması üzerine pencerenin kenarına gelerek dışarı baktı̆̆ını ve "Ben tuğlaları görüyorum” (2012) dediğini söylemektedir. Williams'ın ifadesiyle Meisner'e göre "verili durum, kabul ettiğimiz ve onunla yaşadığımız bir şeydir. Hayali olan ise kafanızdadır" (Williams, 2018). Dolayısıyla oyuncu 'verili koşullara inanmaz'; fakat 
onunla 'gerçekten yaşar'. Bunu "balıklar suya inanmaz ama suda yüzerler" sözleriyle ifade eder. Meisner'in 'gündüz düşleri' olarak bahsettiği oyuncunun sahneye canlılıkla girebilmesini sağlamak amacıyla yapılan hazırlık (preparation) kısmına dahil ettikleri ise sahne üzerine değil sahne gerisine aittir (Meisner ve Longwell, 1987, s.84). Oyuncu sahneye girdiği anda karşısında gördüğü hazırlıkta düşündüğü kişi değil yine sahne arkadaşıdır.

Meisner için oyunculuğun temelini oluşturan 'verili koşullar altında gerçekten yaşama' düşüncesindeki 'gerçekten yaşama' ifadesiyle neden bahsettiğini anlamak hem metodunun pratiklerinin altındaki prensibi öğrenmek hem de oyuncunun sahne üzerindeki gerçeklik algısına yaklaşımını anlamak açısından önemlidir. Meisner'e göre, sahne üzerinde gerçekten yaşamak için oyuncunun gerçekleştirmesi gereken dört temel koşul olduğu söylenebilir. Bunlardan ilki, 'yapma gerçekliğidir':

"[...] 'Yapma gerçekliği. Peki, bunun ne demek olduğunu nasıl bileceksiniz? Açıklayacağım'. Kısa bir duraklamadan sonra sorar 'Beni dinliyor musunuz? Beni gerçekten dinliyor musunuz?' Öğrenciler koro halinde cevap verir, 'Evet, evet'. 'Dinliyormuş gibi davranmıyorsunuz; dinliyorsunuz. Gerçekten dinliyorsunuz. Öyle mi dersiniz?'. [...] 'Bir şey yapıyorsanız onu gerçekten yapın!' [...] 'Şimdi bir dakika için beni dinleyin. Sadece kendiniz için dışarıda duyduğunuz arabaların sayısını dinleyin'. [...] 'Kaç tane araba duydunuz?'. [...] 'Kendiniz olarak mı duydunuz yoksa bir karakteri mi oynuyordunuz?'. [...] 'Bu bir karakterdir"” (Meisner ve Longwell, s. 16 -17).

Birinci koşulu açıklığa kavuşturmak için Meisner ile öğrencileri arasındaki geçen bu diyalogda olduğu gibi, Scott Williams da öğrencilerinden etraflarındaki sesleri dinlemelerini ister ve aradan geçen sessizlikten sonra sorar: "Ne duydunuz?" (Meisner ve Longwell, s. 17). Bundan sonra gelen ikinci soru ise "Oynuyor muydunuz?" olur ve ekler: "Meisner'e göre 'oynuyordunuz" (Meisner ve Longwell, s. 17). Buradaki 'oynamak' ifadesi öğrencilerin '-mış gibi yapamayarak', dinlemenin nasıl olacağı ile ilgilenmeyerek, gerçekten dinlemeleri sonucunda oluşan yapma gerçekliğine yaptıkları yatırımdır. Üstelik yapma gerçekliğine yapılan bu yatırım sırasında oyuncu bunu bir karakter olarak dinliyormuş gibi davranmamalıdır. Karakter, oyuncu verili koşullar içinde yapma gerçekliğine yatırım yaptığında belirir.

Buna ek olarak, oyuncunun yapma gerçekliğine yatırım yaparken, sahne üzerinde bulunduğu süre boyunca izlenmekten doğan gerilime çözüm olarak sunulan dördüncü duvar 
fikrini reddeden Meisner 'kalabalık içinde yalnızlık' (public solitude) anlayışını kullanmıştır. Bu anlayışa göre, tıpkı kalabalık bir metroda kitap okuyan yolcunun durumu ya da ailesinin yanı başında evcilik oynamaya dalmış küçük bir kız çocuğunun yaptığı gibi oyuncu da izleyicinin varlığını yok saymayarak kalabalık içinde yalnızlık halinde yapma gerçekliğine yatırım yapmalıdır. Bu haliyle, oyuncuda hâkim olan "seyirci için” oynama düşüncesinin yerini 'seyircinin şahitliğinde' oynama hali alır ve kalabalık içinde yalnızlık prensibiyle yapma gerçekliğine yatırım yapan oyuncu, gerçekten yaşamanın önemli koşullarından birini yerine getirmiş olur (Meisner ve Longwell, 1987, s. 43-44).

Gerçekten yaşamanın ikinci koşulu olarak Meisner, oyuncunun var olan duygusunu değiştirmeye çalışmaması gerektiğini 'nehir' ve 'kano' benzetmesi üzerinden anlatır. Meisner'e göre oyuncunun duyguları bir nehir, nehrin üzerinde yüzen kano ise oyunun metnidir. Kano, nasıl nehre nasıl akması gerektiğini söyleyemez ve nehrin akışının niteliğini alarak ilerlerse, oyun metni de oyuncuya hangi duyguda oynaması gerektiğini söyleyemez. Dolayısıyla kanonun nehir üzerinde ilerleyişi yani metin vücut bulması, nehrin ak1şına yani oyuncunun duygularına bağlidır (Meisner ve Longwell, 1987, s. 115-116). Oyuncu tıpkı sınıfta Meisner'in öğrencilerinden dışarıdaki araba seslerini dinlemelerini isterken olduğu gibi '-mış gibi' yapmamalı, o anda kendisinde olmayan bir duyguyu oynama çabasına girmemelidir. Oyuncunun sahne üzerinde gerçekten yaşaması metindeki

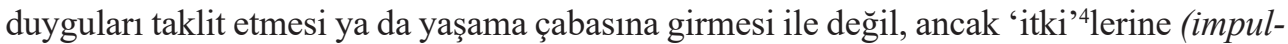
se) göre hareket etmesiyle mümkündür. Metinde olması gerektiği varsayılan duyguya ulaşma çabası oyuncuyu zihnine ve kendiyle ilgilenmesine yönelerek anın gerçekliğinden uzaklaştırır. Oysa, oyuncu metnin tıpkı kano ve nehir örneğinde olduğu gibi kendi duygularının niteliğini alarak ilerlemesine izin verdiğinde organik bir akış başlayabilecektir.

Üçüncü koşul, oyuncuya sahne üzerinde etki eden şeyin kaynağıyla ilgilidir. Adler'e göre oyuncuyu oynatan onun hayal gücü iken, Meisner bambaşka bir açıdan bakarak 'çimdikleme ve ah' (pinch and ouch) prensibiyle oyuncuya olan şeyin kendisine değil diğer kişinin ona ne yaptığına bağlı olduğunu söylemektedir. Oyuncu kendiliğinden '-mış gibi yaparak' tepki vermeyecek, oyuncunun 'ah' dediği şey diğer kişi tarafindan çimdiklenmesiyle ortaya çıkacaktır. Burada anlatılmak istenen, oyuncuya olanın ve

4 İtki ile ilgili olarak Freud, Kernberg, Spinoza, Lacan gibi isimlerce farklı kuramlar ortaya atılmıștır. Basitçe ifade edilecek olursa, itki ya da daha genel bir ifade kullanıldığında "dürtü", Vehbi Keser'in İçeriden Gelen başlıklı makalesinde olduğu gibi kişiyi içeriden dürterek ona eyleme enerjisini veren yani içeriden gelen olarak tanımlanabilir (2014, s. 35-40). 
oyuncunun verdiği karşıllğın (eylemin) kendisine değil diğer kişiye bağlı olduğudur (Meisner ve Longwell, 1987, s. 34). Meisner'in altını çizdiği gibi buradaki yapma hali oyuncunun diğer kişiye verdiği itkisel karşılık ile gerçekleşir.

Oyuncunun gerçekten yaşaması için yerine getirmesi gereken dördüncü koşul, diğer üç koşulun gerçekleşmesi için gereklidir. Buna göre, oyuncu sahne üzerindeyken an be an gözlem yapmaya (dinlemeye) ve karşıllk vermeye devam etmelidir. Burada gözlemden kastedilen sadece görme duyusuyla tespit edilen ayrıntılar değildir, oyuncu karşısındakinin ses tonundan kendisine yakınlığına, konuşma şeklinden mimiklerine kadar; özetle tüm davranışını gözlemlemeli ve karşılık vermelidir. Oyuncu, karşısındaki kişiye tüm dikkatini vererek, ancak kendi savunma mekanizmasını geçmesini engellemeden ona kendini açarsa duygusal olma ya da herhangi bir şey hissetme çabasına gerek kalmayacak; çünkü her şey organik şekilde gerçekleşecektir (Santana, 2006).

Oyuncu bu dört koşulu gerçekleştirebildiği oranda 'gerçekçi' (sahici) olmaz, gerçekten yaşar. Oyuncunun bu dört koşulu deneyimleyerek idrak etmesini ve onun şimdi ve burada olmasına olanak vererek gözlem yapma ve karşıllk verme becerisinin gelişmesini sağlayan yöntem Meisner tarafindan geliştirilen tekrar egzersizlerine dayanmaktadır. Tekrar egzersizlerinin ortaya çıkışının ardında, Meisner'in içinde düşünsellik olmayan bir egzersiz yaratma isteği yatmaktadır. Meisner, bu egzersizler ile oyuncunun kendine yönelik zihinsel manipülasyonunu ortadan kaldırmak ve tüm o zihinsel etkinliği bertaraf ederek itkinin geldiği yere ulaşmak istemektedir (Meisner \& Longwell, 1987, s. 36). Buna göre, tekrar egzersizleri aracıllğ̆ ile oyuncunun deneyimleyerek ulaşmasının istenildiği dört temel çıktı vardır. Tekrar egzersizlerini yaparken; birincisi, Meisner'in söylediği gibi "Kendiniz dışında bir şeye bağlısınızdır"; ikincisi, "Gerçekten yaptığınızda, yaparken kendinizi izlemeye zaman bulamazsınız”; üçüncüsü, "Hepsi çok somut, 'yapılabilir' şeyler gibi görünür”; ve dördüncüsü "Bir şey yaptığınızda onu yapıyormuş gibi yapmak yerine gerçekten yaparsınız" (Meisner \& Longwell, 1987, s. 24).

\section{Meisner ve Adler'in Oyunculuk Yaklaşımlarının Sahne Üzerindeki Gerçeklik Bağlamında Karşılaştırılması}

Stella Adler'in, Paris'te Stanislavski ile çalışması sonrası Stanislavski'nin oyunculuk metodunda yaptığı vurgunun coşku belleğinden verili koşullara kaydığını Grup Tiyatrosu'nda yapılan toplantıda açıkladığı, Strasberg'in bu açıklamaya karşı çıkarken, Meisner'in Adler'in yanında yer aldığından bahsedilmişti. Ancak önceki başlıklar altında in- 
celendiği gibi Meisner ve Adler'in yıllar içinde geliştirdikleri oyunculuk yaklaşımları ve her birinin bu yaklaşımlara dair yazdıkları göstermektedir ki Adler ve Meisner'in tartışmaya kapalı tek ortak noktası coşku belleği kavramına karşı çıkmış olmalarıdır. Bu iki yaklaşım, onların karakter, hayal gücü, eylem, oyuncunun partneriyle ilişkisi gibi anahtar kavramlar üzerinden incelendiğinde birbirinden oldukça ayrışmakta ve bu ayrışma oyuncunun sahne gerçekliğine dair algılarının — her ikisi de temsili oyunculuğa karşı olsalar da- bambaşka olduğunu göstermektedir.

Bu noktada, Meisner ve Adler'in kullandıkları ifade biçimlerinin zaman zaman benzerlik göstermelerine rağmen, farklı noktalara kayan oyunculuk yaklaşımlarında onları karşlaştııırken herhangi bir bulanıklığa yer vermemek amacıyla gerçek ve gerçekçilik arasındaki ayrımın netleştirilmesi yerinde olacaktır. Gerçekçilik ve inandırıcılığın birbirini temsil eden kavramlar olduğunu göz önünde tutarak Meisner'in inandırıcıllı̆ı̆ın seyircide olduğu oyuncunun ise yapma gerçekliğine yatırım yaptığı söylemini değerlendirdiğimizde gerçeklik algısının gerçekçilik üzerine değil gerçeklik üzerine kurulu olduğu anlaşılmaktadır. Adler'in yaklaşımında ise oyuncunun sahne üzerindeki her anında bir gerçeklik kaygısı güdüldügü görülmektedir. Oyuncu yaptığı her şeyi ince ince üzerine çalışarak yani zihni yardımıyla 'gerçek' haline 'getirmelidir'.

Bu bağlamda, Meisner ve Adler' in oyunculuk yaklaşımlarındaki farklılıklardan ilki karakter üzerinedir. Barter, Stella'nın Meisner'den tamamen farklı olarak oyunculuk yaklaşımında ilk olarak karakterden yola çıktığını söylemektedir. Adler, karakterin nasıl biri olduğu; nasıl yürüdüğü, nasıl konuştuğu, nasıl bir sosyal çevreye mensup olduğu, hangi dönemde yaşadığıyla başlayıp daha sonra kişinin gerçeklik hissi üzerinde çalışmaya dönmektedir (Santana, 2006). Daha önce bahsedildiği gibi, Adler'in 'karakter unsurları' başlığı altında rol kişilerinin nasıl insanlar olduğunun kararlaştırılmasını öngördüğü düşünüldügünnde oyuncunun eylemini hangi unsurların etkisi altında gerçekleştireceğinin de çerçevelendirilmiş olduğu ve karaktere dair kararların yöntemde önemli yer tuttuğu görülebilir.

Öte yandan, Meisner'e göre oyuncu bir şeyi gerçekten yaptığında karakter hakkında konuşmaya gerek yoktur. Oyuncu, yapma gerçekliğine yatırım yaparak gözlem yapıp karşılık verdiğinde karakter ortaya çıkmış olur. Oyuncu bir karakteri oynamaz; karakter oyuncunun yaptığı şeyde verili koşullar içinde belirir (Meisner ve Longwell, 1987, s.24). Bu süreçte, Adler'den farklı olarak metnin verdiği bilgiler dışında oyuncu kim/ ne/ ne zaman/ nasıl/ neden sorularına cevap vermek zorunda değildir. Özetle, Adler'in yaklaş1- 
mına göre karakter belirli sorular cevaplanıp, belirli seçimler yapılarak inşa edilirken, Meisner'e göre "Karaktere dair ortaya çıkan tercihler zihinsel bir seçimin sonucu değil içgüdüseldir. Fikirler üzerine seçim yapılmaz” (Meisner ve Longwell, s. 188). Buna bağlı olarak, karakterin ortaya çıkışı bakımından Adler'in yaklaşımına göre sahne üzerindeki gerçeklik karakter bağlamında bir tasarıma dayanırken, Meiser için organik şekilde anda ortaya çıar. Bu koşularda, oyuncunun sahne üzerindeki gerçeklik algısını, oyuncuyu bir tasarımı gerçekçi şekilde gerçekleştirmeye mecbur bırakmayan ikinci yaklaşımın daha çok beslediği öne sürülebilir.

Meisner ve Adler'in ayrıştıkları ve oyuncunun sahne üzerindeki gerçeklik algısına dair ikinci konu eylemdir. Her iki isim de sahne üstündeki gerçekliğin 'yapmak' ile doğrudan bağlantılı olduğunu savunsa da çalışmalarının detaylarına bakıldığında bahsettikleri eylemlerin gerçekleşme süreçleri birbirinden oldukça farklıdır. Meisner, oyuncunun yapma gerçekliğine yatırım yaparak gerçekten yaşayabileceğini söylerken; Adler'e göre eylemler tek tek analiz edilmeli; omurgaları çıkarılmalı, üzerinde ayrıntılı olarak çalışılmalı ve en küçük eylemin dahi kas hafızasına alınması sağlanmalıdır. Adler'in yaklaşımında tıpk1 karakterde olduğu gibi eylem, metin temelli ilerlenerek belirlenmektedir. Öte yandan Meisner için oyuncuyu "gerçekten yaşatan" şey "açıkça gözlemlenen davranış anına verilen itkisel karşılıktır" ve bu tanım gereği anda belirir (Williams, 2012).

Kimi yazarlarca, Meisner ve Adler'in oyunculuk yaklaşımlarının ortak özelliği olarak değerlendirilse de birbirlerinden ayrıldıkları bir diğer nokta hayal gücüdür. Adler, oyuncuyu harekete geçiren, eyleminin gerçekliğini belirleyen bir yardımcı olarak hayal gücünün önemini vurgular ve sahne üzerinde hayal gücünden geçmeyen her gerçeğin yalan olduğunu ileri sürer (Adler, 2006). Meisner ise hayal gücünün temel olarak sahne üzerinde değil oyuncuya belirli bir canlılık getiren 'hazırlık' aşamasına giriş olarak kullanılmasından yanadır (Meisner ve Longwell, 1987, s. 76-78). Oyuncu sahne üzerine geldiğinde şimdiki zamana dönmeli ve sahne üstündeki partnerini hayal ettiği kişi değil oyuncu arkadaşı olarak görmeye devam etmelidir (Williams, 2018, s. 20). Sahne üzerinde oyuncunun an be an gözlem yapıp karşılık vermesini isteyen Meisner için oyuncunun zihnine dönme durumu elimine edilmelidir. Bu bağlamda, Adler'in hayali koşulları ile Meisner'in verili koşulları birbirinden tamamen farklıdır. Adler'e göre hayal gücü oyuncuyu harekete geçiren bir olmazsa olmazken Meisner'e göre oyuncuya olan şey hayal gücüne değil karşısındaki diğer kişinin oyuncunun üzerindeki etkisine bağlıdır. Ayrıca, 'hayali' kelimesi kullanıldığı an oyuncuların bakışlarının donuklaştığı, boşlukta bir şeyler ara- 
dıkları ve şimdiki andan uzaklaştıkları söylenmektedir (Williams, 2020). Bu görüşe göre, sahne üzerinde oyuncunun söylediği hiçbir şeyi kendi hayal gücünden geçirmeden söylememesi gerektiğine vurgu yapan Adler'in bu yaklaşımının oyuncunun şimdiki andaki mevcudiyetini azalttı̆̆ söylenebilir.

Son olarak, Adler ve Meisner'in oyuncunun sahne üzerindeki gerçeklik algısına yaklaşımlarında oyuncunun sahne üzerinde yaptıklarını dayandırdıkları 'gerekçelerin' birbirinden ayrıştığı söylenebilir. Adler'e göre oyuncunun eyleminin büyüklüğünü belirleyen onun arkasında oyuncunun kişisel olarak belirlediği metnin verili koşullarında olmayan nedendir. Oyuncu tarafindan belirlenen bu neden, oyuncunun sahnede olduğu süre boyunca durmaksızın sürmektedir. Dolayısıyla, oyuncu yine sahne üzerindeki gerçeklikten bağımsız olarak sahne dışında yapılan seçimlere bağlı olarak davranmaktadır. Eylemin bu şekilde gerekçelendirilmesinin Meisner'in ileri sürdüğü 'çimdikleme' ve 'ah' prensibinin zıttı bir yaklaşım olduğu söylenebilir. Meisner'e göre oyuncuya olan şey ve dolayısıyla oyuncunun olan şeye verdiği karşılık (eylem) partnerine bağlıyken, Adler'in yaklaşımında oyuncunun eylemi daha önce alınmış bir karara bağlı olarak belirlenmiş olur. Oyuncunun şimdi ve burada olana göre karşılık vermesi ile kendi nedenselliğini sahne dişında belirleyerek buna göre eylemde bulunmas1 arasındaki fark, sahne üzerinde oyuncunun pozisyonunu 'gerçekten yaşayandan' 'inşa edene’ kaymasıdır. Oyuncunun sahne üzerindeki algısında bu inşa süreci önceki bölümlerde bahsedilen tüm unsurlar için geçerlidir: "Hazırlığınızı adamakıllı yaptığınızda odaya nasıl girmeniz gerektiğini bilirsiniz; sahneyi nasıl kullanmanız gerektiğini de, sahnede gezinmeyi nasıl haklı göstereceğinizi de. Hepsini içten bir biçimde yapmayı öğrenirsiniz” (Adler, 2006, s. 55). Bu bağlamda bakınca, Adler için oyuncunun sahne üzerindeki geçeklik algısının gerçekçi ya da diğer bir ifade ediliş biçimiyle sahici yapmaya dayandığ 1 iddia edilebilir.

\section{Sonuç}

Stanislavski'nin birinci dönem çalıșmalarından yola çıkılarak bakıldığında oyuncuda belirli bir duyguyu gerçekten yaratmayı amaçlayan coşku belleği kavramı oyuncunun geçmişinde seçtiği bir anısının yeniden çağrılması prensibi üzerine temellenmekteydi. Dolayısıyla, oyuncunun yaşadığı duygusal durum sahnenin gerçekliğinden farklılık göstermekteydi. Sahne üzerinde oyuncunun yaşadığı andaki gerçekten bağımsız, geçmişte yaşadığı bir olaya verdiği duygusal tepkinin reprodüksiyonu denilebilirdi. İkinci dönem olarak da adlandırılabilecek son döneminde ise, Stanislavski'nin gerçek duygulara ulaşma yolunda coşku belleğine üzerine yaptığı çalışmaları verili koşullara ve fiziksel 
eylemlere yönelterek, duyguların anahtarının fiziksel eylemlerde yattığı fikrini savunmaya başladı (Toporkov, 2017, s. 92-112). Ancak bu anlayışa göre sahne üzerinde yapılacak bu eylemler önceden belirlenmektedir.

Stella Adler de bu bağlamda, öncülü Stanislavki gibi fiziksel eylemler metodunun peşinden gitmiş ve yine Stanislavski'nin oyunculuk metodunda önemli bir yere sahip olan 'hayal gücüne' vurgu yapmıştır. Oyuncunun eylemlerini gerekçelendirmesi ve karakteri inşa etmesi de metne dair fikirler üzerinden gerçekleşmektedir. Eylemler ve karakter bir keşiften ziyade önceden oyuncu ya da yönetmen tarafından alınan kararlara, metne ve metnin hayali koşullarına dayanmaktadır. Stella Adler'in bu anlamda oyuncunun sahne üzerindeki gerçeklik algısına dair benimsediği oyunculuk yaklaşımı, Meisner'in karşı çıktı̆̆1 entelektüel bir yaklaşımın örneğidir. Oysa Meisner'e göre oyuncunun savaşması gereken en önemli problemlerden biri zihindir. Zihin elimine edilmeli, oyuncu sahnede itkisel olarak hareket etmelidir. Çünkü itki zihinden değil bedenden gelir, kurgulanmaz. Meisner'de itkilere olan bu vurgu Adler'de oyuncunun hayalgücü ve eylemlere, karaktere dair sahneyi oynamak üzere yaptı̆̆ı hazırlık üzerinedir.

Sonuç olarak, Meisner'in oyunculuk yaklaşımı, oyuncunun sahne üzerindeki gerçekliğine, var olan duygu durumunu kabul ederek; dikkatini kendi üzerinden partnerine yönelterek; gözlemine itkisi doğrultusunda karşılık vererek ve bu esnada kendi fikirlerine dayanarak eylemde bulunmak yerine partnerinin etkisiyle harekete geçerek ulaşabileceği düşüncesine dayanmaktadır. $\mathrm{Bu}$, oyuncunun anın gerçekliğine göre hareket etmesini sağlamaktadır (Williams, 2018). Diğer yandan, Stella Adler'e göre karakterin, eylemlerin, hayal gücü ve gerekçelendirmenin detaylıca inşa edilmesi ve yeterince hâkim oluncaya kadar inşa edilen üzerinde çalışılması ile sahne üzerinde sahicilik mümkün olabilir. $\mathrm{Bu}$ bağlamda, Adler'in, oyuncunun sahne üzerindeki gerçeklik algısı oyuncunun sahne üzerinde sahici yani gerçekçi olması fikri üzerine kuruluyken, Meisner'e göre oyuncunun sahnede keşfederek gerçekten yaşamasına bağlıdır.

Hakem Değerlendirmesi: Dış bağımsız.

Çıkar Çatışması: Yazar çıkar çatışması bildirmemiştir.

Finansal Destek: Yazar bu çalışma için finansal destek almadığını beyan etmiştir.

Peer-review: Externally peer-reviewed.

Conflict of Interest: The author has no conflict of interest to declare.

Grant Support: The author declared that this study has received no financial support. 


\section{Kaynakça/References}

Adler, S. (2006). Aktörlük sanatı (N.U. Özüaydın, Çev.) İstanbul: Mitos Boyut Yayınları.

Keser, V. (2014). Psikanaliz yazıları. Küey, A.D., İkiz, T., Kayaalp, M. L., Tükel R. (Ed.), İçeriden Gelen (s. 35-40). İstanbul: Bağlam Yayıncılık.

Meisner, S. \& Longwell, D. (1987). Sanford Meisner on acting. New York: Vintage Books.

Özüaydın, N. U. (2015). Bir oyunculuk tekniği olarak coşku belleğinin analizi. Tiyatro Araştırmaları Dergisi. 39 (1), 23-36.

Santana, J. A. (Director). (2006). Sanford Meisner acting class [DVD]. United States: Open Road Films.

Stanislavski, K. (2008). An Actor's work. (Benedetti, J. Trans.) New York, NY: Routledge.

The Stanford Meisner Center. (2018). Our history. Erişim adresi: https://www.themeisnercenter.com/history.html

Toporkov, V. (2017). Stanislavski provada. (C. Yalaz, D. Dalyanoğlu, Ö. Eren, Çev.). İstanbul: BGST Yayınları.

Whyman, R. (2012). Oyunculukta Stanislavski sistemi. Modern Performans Alanındaki Etkisi. (H.Gür, Çev.). Ankara: Dost Kitabevi.

Williams, S. (2018). Meisner oyunculuk tekniği notlart. İstanbul: Kadir Has Üniversitesi.

Williams, S. (2012, 22 Ekim). The buble of belief. [Blog yazısı]. Erişim adresi: https://www.impulsecompany.co.uk/ scott-s-blog/ 